\title{
Control of the Transaction Cost of the Business Purchase Based on the Block Chain
}

\author{
Zhihong $\mathrm{Li}^{1, *}$ \\ ${ }^{1}$ Business School, Jianghan University, Wuhan, Hubei 430056, China \\ *Corresponding author. Email: linanwudingbang@163.com
}

\begin{abstract}
The fierce competition in the market makes the enterprise enter into the times of the meager profit. Strict control of the cost in the production \& operation becomes an inevitable trend. Usually, the cost of the enterprise consists of material purchase, processing and personnel management, etc. Of the different costs, the expenses of the material and human labor are becoming more and more transparent and leave less and less room to be controlled as the competition is more and more sharpened in the market. So, the enterprise must seek for the benefits from its various management like people, purchase and marketing, etc. Among these, the management of the purchase transaction cost is quite important. Therefore, the paper makes a relatively full study of the items concerning the transaction cost. First, the paper disentangles the business purchase and its features, then exposes the components of the transaction cost and its problems existing in the business purchase, and finally puts forward some tactics to control the transaction cost during the business purchase based on the block chain.
\end{abstract}

Keywords: Transaction cost, Business purchase, Block chain.

\section{INTRODUCTION}

The globalization of the market brings the enterprise more chances and also risks, too. On one hand, it makes it easy for the enterprise to do business internationally. On the other hand, it forces the enterprise to be obliged to deal with various intricate relationship problem coming from the trading, politics, etc. The business purchase is the very case. Due to the market rival globally, the price of various materials is quite clear and transparent and every enterprise is able to fully understand the market and enjoys the relatively low price. But, because of the complicated purchasing relationship, the enterprise has to pay the other cost happening in the transaction cost which may greatly hinder the acquiring of the profits. So, how to control the transaction cost during the business purchase is quite a troublesome and obliged issue for the enterprise to make profits.

\section{ENTERPRISE PURCHASE}

\subsection{Connotation of the Enterprise Purchase}

The purchase of the enterprise refers to those activities by which the enterprise can obtain the needed items or service in the market so as to keep its processing or operation going normally. Usually, it mainly includes general procurement and service outsourcing [1]. The former means that the buyer issues the demand messages to the supplier in the form of the purchase order, arranges and follows the overall logistics course to ensure to get all the bought items on time and to support the normal operation of the business according to the purchase agreement and plan of the material requirement. The latter means that the enterprise outsources its all or partial purchase business to the professional supplier outside so that it may focus on its main business. Also, the outer professional supplier of the supply chain may well master the market information and can support the buyer in cutting down the purchasing cost. 


\subsection{Features of the Enterprise Purchase}

The enterprise purchase is a kind of economic activity. Inputs and outputs are its important sections. During the purchase, various expenses in the supplying chain form its purchase costs[2]. In the meanwhile, its inputting into the demanded materials or equipment can assure the normally running of its business, in which the purchase outputting are realized. Also, the enterprise purchase is an integrated process of the commodity, logistics, funds, information and ownership transfer. By purchase, the commodity moves from the supplier to the buyer. Accompanying with the moving of the commodity, its ownership is transferred from the supplier to the buyer by way of transaction. Also, the commodity must see series of physical activities like transportation, warehousing, package, loading \& unloading and even reprocessing, etc. In the course of commodity moving, the concerned information is obliged, so timely and precise information passage is quite necessary. What's more, when the commodity reaches each section such as transporters, warehouse and so forth, its value is added since the stakeholders in each section pay their time and labor. This leads to a result: the value or price of the commodity got by the buyer is bigger than that in the supplier.

\subsection{Transaction Cost Components and Concerned Problems in the Purchase for the Enterprise}

Transaction costs was first put forward by Coase, R.H.[3]. He thought that the transaction cost meant those to find out the relative price in organizing the production by the price mechanism, the expenses to negotiate and sign a contract for each exchange in the market and all the other payment in adopting the price mechanism. Simply speaking, it refers to the price which people pay of their free will for the purpose of reaching transaction in certain social conditions. It consists of various expenses or costs in information transmission, ads, negotiation, contract sign and implementation, supervision and transportation relative to the market. Afterwards, Williamson made a further study of the transaction cost. He thought that the transaction cost includes those of seeking, information, bargaining, decision making, transaction supervision and contract violating, etc. In light of Williamson, the roots to cause the transaction cost come from the bounded rationality, opportunism, asset specificity, uncertainty and complexity, small numbers, information asymmetric, and atmosphere[4].

In essence, due to the professional division of labor in the business, the market mechanism and the pursuit to the economic efficiency, some problems concerned the transaction cost in the purchase of the enterprise are inevitable[5].

First, because of uncertain and complex transaction conditions, asymmetric information communication and individual opportunism in nature, the professional division of labor makes the information communication lack of validation in the purchase. As a relatively independent function, the purchase department usually more cares for the buying of the material. The buyer plays only a role of the intermediary between the material planner and the supplier. Once the message is misunderstood or distorted, the surplus or insufficiency of the materials for the processing may happen, which will cause the overloaded stock or the order unable to be fulfilled.

Second, the asset specificity and the small numbers in the purchase of the business let the buying activities lack of the supervision control. Commonly, the material purchase in an enterprise is often held in some department or several people. This kind of proprietary in the transaction leads to the market malfunction and few restraints. As a result, opportunism and rent seeking grow and lead to an increase of the supervision cost and exchange expenses.

Third, the relationship bounds with the supplier hard to be mastered may cause some unexpected expenses in the business purchase because the transaction participants are limited by their mind, intelligence, experience and cognition and so on[6]. On one hand, if the participants are not trusted each other or lie in a state of opposition, the transaction form may over-stressed. This will bring about the unnecessary cost. On the other hand, if the relationship with certain suppliers is too good, the reliance on them might occur, which will hinder the buyer from seeking for the new better supplier and the competition in the purchase will be weakened. In this way, the benefits of the enterprise will be harmed. 


\section{CONTROL OF THE TRANSACTION COST OF THE BUSINESS PURCHASE BASED ON THE BLOCK CHAIN}

\subsection{Connotation and Features of the Block Chain}

The block chain is a new kind of application model of the information \& network technology in the point-to-point transmission, distributive data storage, encryption computation, and commonly identical mechanism, etc.[7] It has the features of decentralization, trustworthy and traceability and so on.

\subsection{Integrating the Enterprise Purchase and the Block Chain}

The enterprise purchase is a supplying system consisting of logistics, information flow and funds circulation. Its stakeholders include suppliers, manufacturers, wholesalers, retailers and users and so forth. Their favorable coordination promotes a normal run of the whole supplying chain. But as a rational body, any stakeholder does business exchange only in the angle of its owner benefits. Also, being an independent stakeholder, their concerned information is kept separately in the different sections of the whole supplying system, which leads to the lack of the information transparency. These phenomena may cause reverse selection or moral hazard. That's to say, the stakeholder may provide the others more information favorable for itself. In this way, such problems may occur: some participants during the purchase are hard to get the timely precise business messages and to respond to the exchange on time. Therefore, the efficiency of the supplying system is badly affected. More seriously, once disputes among these stakeholders happen, due to the complexity of the whole supplying system, the handling of the disputes may become rather difficult or even impossible because of the insufficient proof. In the current economic globalization, it's more difficult for the stakeholder to follow the various business activities, which may lead to some fake and shoddy items. The openness and justice and equality of the market is facing severe challenge. The block chain, with its traceability, trustworthy, confidentiality and decentralization, can offer quite good approaches in managing and supervising the cooperative activities of the supplying system in the business purchase[8].

\subsection{Control of the Transaction Cost Based on the Block Chain}

First, the point-to-point communication among the relative participants based on the block chain can make the transaction data pass more punctuate. This can assure the stakeholder able to find out the problem happening in the business in time and solve it[9]. Therefore, the seeking cost to collect such information as commodity and target customers and the documentary cost aiming at acquiring the messages like exchanging the information with the target.

Second, the confidentiality based on the block chain technology can fully insure the security of the transaction data and also the extensiveness of the transaction activity[10]. The confidentiality technology of the block chain consists of digital signature, encoding and decoding with the pair of public key and private key. Take the bit-coin for example, the bit-coin user can get a pair of public key and private key. The public key can be seen by all the users in the block chain while the private key can only be kept by the user himself or herself. All the transactions and signature must be encoded with the private key of the user, which can't be known by the others. This pair of the keys is regarded as the identity of the bit-coin in the block chain. With this principle, the public key of the business purchase transaction can be issued to all the participants of the block chain network. This can increase the extensiveness of the supplying and demanding information. In the meanwhile, the private key is held only by the trader himself or herself. This pair of public and private keys can be seen as an identity of some transaction. This kind of the confidentiality mechanism of the block chain will do benefits to cutting down the contract signature cost like negotiating and decision making, because all the concerned bargaining activities can be done in the block chain network.

Third, the data unable to be falsified and the kept time mark can be used as the proof to deal with the disputes among various participants in the supply chain. This feature may do benefits to cut down the information seeking cost and the transaction supervision cost that supervises the transaction stakeholders if they have done the business according to the relative trade agreement such as product trace, supervision and reception 
and so forth. In the meanwhile, the combination between the data unable to be distorted and the transaction able to be traced can solve the problem of the fake \& inferior items in the flow of the supply chain, which will put an end to the possibility of violating the trade contract and then reduce the cost of the breach of the contract.

\section{CONCLUSION}

To sum up, the control of the transaction cost during the business purchase in the current global market conditions is a tricky and complicated issue. It concerns all kinds of problems such as information, bargaining, decision making, supervision, anti-contract, disputes and constrains and so on. Facing these problems, the enterprise should be well ready in the concerned skilled personnel, technology and commercial management, etc. Among these elements, the block chain and its technology, with its point-to-point communication, trace-ability, confidentiality and kept time mark, etc, can better serve the business purchase and will do many benefits it.

\section{AUTHORS' CONTRIBUTIONS}

This paper is independently completed by Zhihong Li.

\section{ACKNOWLEDGMENTS}

The paper is funded by the Discipline Group of the Integrative Management Between Economy and Industry in the City Circle, by the Wuhan Studies Institute, Hubei, China(IWHS20172001), and by Research Center on the Development of the Manufacturing Industry of the Wuhan City Circle, China(wz201607).

\section{REFERENCES}

[1] https://baike.baidu.com/item/\%E9\%87\%87\%E $8 \% \mathrm{~B} 4 \% \mathrm{AD} / 4232146 ? \mathrm{fr}=$ aladdin

[2] Pinghua Zeng, Yunmei Chen, Liqiong Li. Research of the Enterprise Cost Control in the Angle of the Supply Chain. Business Circle Modernization. No.9, 2009

[3] Coase R.H. The-Nature-of-the-Firm, 1937. https://wenku.baidu.com/

[4] Williamson. The Economic Institutions of Capitalism. http://www.ishare5.com/
[5] Zhiqiang Liu. Research of the Transaction Cost in the Purchase Management of Company M. 2013, https://xueshu.baidu.com/

[6] Weimin Ma, Yin Zhang, Gang Li. Analysis of the Competition for the Inside Purchase Management Model with the Transaction Cost \& Holding Cost. Operation \& Management, 2018, https://www.ixueshu.com/

[7] Yalan Wei, Yuanjie Rong, Xin Liu. Analysis of the Future for the Block Chain Technology in the Supply Chain Management Center. Invitation of the Procurement Tenders Management, 2019

[8] Jianming Zhu, Yonggui Fu. Synergy Authentication Model of the Dynamic Multiple Centers in the Supply Chain Based on the Block Chain. Network \& Information Security Journal. No.1, 2016

[9] Yaxi Sun, Xinxin Sun, Wenlong Li. Application Analysis of the Block Chain in the Supply Chain Management. Business Circle Modernization. No.18, 2018

[10] Caixia Cui. Tactics to Control the Transaction Cost During the Enterprise Purchase Based on the Supply Chain. Business Information. No.40, 2017 